\title{
Provide your feedback with a priority in mind: Weighing errors before drawing the red line?
}

\author{
Emna Maazoun ZAYANI \\ English Department, University of Sfax, Tunisia
}

\begin{abstract}
In order to judge the gravity of written errors, teachers generally resort to different sets of criteria. In addition, the majority of error gravity research studies focus on the judgment of native versus non-native speakers. However, little concern has been paid to the role of criteria selection in shaping gravity judgment in the Tunisian context. Therefore, this research attempted to investigate the impact of criteria selection in shaping teachers' judgment of the gravity of written errors. Fifty essays of third year management students were analysed. Fifteen Tunisian teachers participated in the evaluation process. Teachers were classified according to their experience as long teaching experience teachers (LTETs). In order to gauge their judgments, they were to react on a scale item questionnaire using two different criteria: irritation and acceptability. This piece of paper is quantitative in nature. The findings showed that teachers tended to behave differently in reacting to the students' written errors. Therefore, they differed in terms of leniency/severity dichotomy in assessing the gravity of the errors.
\end{abstract}

Keywords: acceptability, error gravity, feedback, irritation, severity judgment

\section{INTRODUCTION}

The field of second language (L2) learning has been a fertile field of research. Error analysis, in particular, is one of the aspects of L2 learning processes that has received much attention from researchers ([1] Eun-pyo, 2002; [2] Kasanga, 2006:65-89). In Tunisia English is learned as a third language after Arabic and French. Therefore, the notions of second language and foreign language are going to be interchangeably used inspite of the awareness of the existing differences. Writing is the forth skill in the learning process which comes after listening, speaking and reading. Writing in nature is difficult, therefore dealing with the writing skill causes some challenges for both teachers and learners ([3] Rivers and Temperley 1978\& [4] AbiSamara 2003). This problematic nature of writing seems to be obvious in learning, teaching, and assessment. Therefore, a review of the literature provides many suggestions concerning the way how to treat errors through weighing them in a priority scale. However, it is to be noted that attributing different priorities to written errors is not very common among instructors in the Tunisian context. Error correction is one of the major areas in language pedagogy and also in the area of teacher's role in language learning. While looking at the types and sources of the errors committed by the students, it is also important to look at how the teachers react to these errors. It is worth noting that the matter of error correction has been reconsidered in the light of error gravity research. Therefore, questions like which error to correct? And when to do so? Translate the link between error-making and teacher expectations ([5] Raimes, 1991). Getting a new vision to the field of Error Analysis through considering the gravity of the errors, helps teachers and practitioners to be more pragmatic in drawing the red lines in their students' papers. This study, however, concerns itself with investigating variability among teachers in assessing the gravity of language errors found in the written exams of third-year management students.

\section{STATEMENT OF THE PROBLEM}

To facilitate the learners' writing task, teachers should have some priorities in dealing with written errors. Therefore, treating errors according to hierarchical order enables the teacher to prioritize his teaching objectives. Hence, this research will be an attempt to investigate teachers' differences in reacting to the study written errors in accounting for two different evaluation criteria.

\section{RESEARCH OBJECTIVES}

1. To investigate teachers' conception of learners' errors.

2. To understand how teachers react to learners' errors when detecting them in their writings.

3. To gauge teachers' tolerance of learners' errors.

4. To determine teachers' categorization of learners' errors. 
5. To assess whether such categorization of learners' errors has an implication on teaching and syllabus design. Therefore, prioritizing errors lets the teacher know which error to tackle first. This informs teaching because it affects syllabus and curriculum design, teaching and evaluating methods (feed-forward instead of feedback) and decision making. Accordingly, this research seeks to shed light on the behavior of a specific community of teachers in relation to learners' errors in writing. It is expected that new perspectives in syllabus design and pedagogical approach be recommended.

\section{RESEARCH QUESTIONS}

The study is guided by three research questions:

1-How do LTETs react to the written errors according to their types in the light of the teaching experience?

2-How will LTETs react to the written errors according to their types in the light of criteria selection?

3-How will written errors be ranked by LTETs in the light of teaching experience and criteria selection?

\section{RESEARCH HYPOTHESES}

The main hypothesis of this study is that teachers' judgmental differences in evaluating learners' written output are due not only to teaching experience, but also to the angle that we choose to perceive error from.

- Positive directional hypothesis:

There are a lot of differences among teachers in responding to the gravity of written errors.

- Null hypothesis:

There are no obvious differences among teachers in treating the seriousness of the written errors.

\section{Defining Learners' Errors :}

\section{LITERATURE REVIEW}

Terms like 'mistake' and 'error' have sometimes been used interchangeably. According to [6] Ellis (2003: 17), "errors reflect gaps in a learner's knowledge; they occur because the learner does not know what is correct". In other words, they occur systematically and they reflect the learner's incomplete knowledge. Errors are related to competence, whereas mistakes are related to performance. [6] Ellis (2003: 17) claims that mistakes "reflect occasional lapses in performance". These lapses could be slips of the tongue, slips of the pen, or slips of the ear. The latter "may provide some clues to how the brain tries to make sense of the auditory signal it receives"[7] (Yule, 2010:161). As an example, "great ape may be heard as grey tape". Thus, drawing a clear cut boundaries between errors and mistakes has always been problematic for English teachers. Moreover, deciding upon the criterion to adopt in making this distinction is more problematic. Therefore, [8] James (1998) has opted for three criteria. The first was the criterion of self-correctability. So, learners are able to correct their mistakes, but they are unable to correct their errors to the exception of advanced learners. The second criterion was consistency, i.e., the learner commits an error if s/he consistently uses a deviant form for a correct target language (TL), but if the deviant forms are random they are mistakes. The third criterion is the frequency of occurrence. That is, errors with low frequency are considered to be mistakes and those with high frequency are errors.

\section{Error Analysis :}

Error analysis comes as a more focused method in approaching learners' errors. Pit Corder is the 'Father' of Error Analysis (EA). It is in his article entitled "The significance of Learner Errors" (1967) that Error Analysis took a new turn. Errors used to be 'flaws' that needed to be eradicated. Therefore, errors used to be seen negatively in the area of language learning and teaching. Analyzing learners' errors systimatically pathes the way to determine areas that need reinforcement in teaching [9] (Coder, 1967). [10] Richards and Schmidt (2002:184) define it as "The study and analysis of the errors made by second language learners." By the same token, [11] Crystal (2003:165) claims that error analysis is "a technique for identifying, classifying and systematically interpreting the unacceptable forms produced by someone learning a foreign language".

[12] Corder (1974:125) notes that Error Analysis (EA) is useful in second language learning because it draws the attention of teachers, syllabus designers, and textbook writers to errors which "... can tell the teacher how far towards the goal the learner has progressed and consequently, what remains for him or her to learn". So, students" ee errors are valuable feedbacks" [13] (Xie \& Jiang, 2007:13). Therefore, one of the main aims of error analysis is to help teachers to be more focused on the assessment of their learners' productions. As a matter of fact, remedial work would be vital to help students avoid the most common errors.

\section{Methodology of error analysis}

The founding father of EA is Corder S. P. His early works present the methodology for EA. [14] [15] Corder $(1967,1973)$ identified a model for EA which included three stages: 
- Data collection

- Description

- Explanation

Other researchers, such as [16] Ellis (1994) and [17] Gass \& Selinker (2008), adopted this model. However, [18] Keshavarz's (2012) expanded this blue print to a fourth step called evaluation of error seriousness. Hence, the following four-step approach was designed:

- Identification of errors

- Description of errors

- Explanation of errors

- Evaluation of error seriousness

For practical reasons, this study duplicated this approach to investigate EA in the Tunisian context.

[18] Keshavarz (2012:168) asserted that EA is "a procedure used by both researchers and teachers which involve collecting samples of learner language, identifying errors, classifying them according to their nature and causes and evaluating their seriousness".

\section{Error Gravity Research}

Error gravity (EG) represents a criterion for error correction, indicating the categories of error which need priority attention. Depending on the seriousness of the error, correction can be decided on who corrects which 'error.' There is a consensus amongst linguists ([20] Burt 1975, and [21] Valdman 1975) that the degree of the seriousness of an error should be given closer attention in the corrective treatment of errors. As [22] Ellis (2013:4) notes that teachers' guides give little advice "on which errors teachers should correct and which ones they should ignore". Additionally, [23] Delisle (1982: 39) states the problem in these words: "if our goal is to achieve absolute linguistic correctness, all errors are equally serious and will be rated accordingly. However, if we define our objectives in terms of communicative success, then we will probably use a different rating scale". Therefore rethinking errors in degrees is important if we want to address their social impact, or "the seriousness of an error" [24] (Ellis, 2008: 961). So, there seems to be an order in which some errors are considered as more serious than others.

\section{Prioritizing errors}

With the advent of error evaluation research, the focus on errors has shifted from the mere description and explanation stages to defining their seriousness and especially identifying which specific error to start with. Therefore, [25] Lee (2003: 164) seems to be aware of this concern through asking the following questions "How can teachers define the gravity of errors? Which errors should teachers mark, and which errors should they leave alone? These are important questions to explore“. In literature there seem to be a consensus upon the effectiveness of selective correction for written errors. For example, [26] Hammerly (1991) claims that error treatment becomes more effective if it is provided systematically and selectively. Therefore, selective correction implies that teachers have to decide which errors should be prioritized for correction. [27] Burt (1975) points out that certain types of errors have higher priorities for correction than others. Moreover, [28] Ferris (2002) makes the following statement: Are all errors equal or some errors are more important than others? Rings the bell to focus on patterns of error, allowing teachers and students to attend to, say, two or three major error types at a time, rather than dozens of disparate errors (Ferris, 2002: 50). The inconsistency in evaluators' judgment of the gravity of L2 errors pushes many scholars and practitioners to think about the criteria upon which the judgments occur. [29] (James, 1977: 116) seems to support this view when he says that ESL teachers probably 'do refer consistently to criteria of degrees of erroneousness when they mark, even though they do not explicitly formulate these criteria'. For example, [30] Hyland and Hyland (2006), employed infringement of rules as his main criterion in judging error gravity." [31] Ferris (1999: 6) similarly suggested that written CF should be directed at "treatable errors" (i.e., errors relating to features that occur in "a patterned, rule-governed way".

Other scholars, however, rely on other different criteria in error treatment. [32] Bartram and Walton (1991) assert that certain types of errors are more important than others. Therefore, it would be necessary for teachers to know the hierarchies of those errors. Although there are a number of different types of available criteria, the most important errors commonly ranked in the literature of EG by the researchers and educators are linked to the following criteria: (1) those that are relevant to the pedagogical focus, (2) those that occur frequently, (3) those that hinder intelligibility (4) those that affect teachers' acceptability (5) those that cause irritation and (6) those that affect comprehensibility. Since this paper concerns itself with irritation and acceptability criteria, the next part will be targeted only to these two criteria.

\subsection{Errors that affect teachers' acceptability}

[33] Bachman (1990) has developed a model of communicative competence which comprised and underlies our perceptions of acceptability. This model has taken all aspects of competence into account with its 
subdivisions. These various aspects are taken into consideration in the evaluation practice. Knowing all these kinds of competence can make learning, teaching processes, and the acceptability judgment easier. In fact, determining some norms to define acceptability remains a very delicate task. Therefore, [34] Corder (1973:101) is in favor of 'a sufficient degree of determinacy to identify some norms and make some statements about what is acceptable and what is not'. If fact, without the validity of acceptability it would be impossible to meaningfully engage in language teaching. [35] Ludwig (1982) found considerable variation in what constitutes acceptability. The latter is defined as language use in a particular context. However, in some other studies acceptability is perceived as a criterion that denotes the degree to which a given error deviates from the linguistic norm. In another study, " respondents judged as least acceptable those errors which, for the most part ,are global and/or are relatively rare violations for native speakers, e.g., word order, it-deletion, tense, relative clause errors, and word choice" [36] (Vann, Meyer, and Lorenz, 1984: 432).

\subsection{Errors that cause irritation}

[35] Ludwig (1982:275) defines irritation as "a function of the speaker/writer's erroneous use of language measured against the characteristics and expectations of the interlocutor". [37] Santos (1988) refers to irritation as the "bother" factor. In other words the reader becomes irritated by the utterance if he feels frustrated by the produced utterance. [38] Khalil (1985:336) defines irritation in his way as "the thing that causes people to stop and take notice of a textual feature". Irritation is used as a criterion in studies by [39] Piazza (1979), [40] Chastain (1980 a), [41] Galloway (1980), and [42] Ensz (1982). Irritability is defined by [35] Ludwig (1982: 275) as "the result of the form of the message intruding upon the interlocutor's perception of the communication". Other studies ([43] Santos, 1987, [44] Vann et al. 1984) would regard irritation as belonging to the hearer/listener despite the communicability of the message. Thus a criterion of irritability on hearing or reading errors may be assumed to be subjective on the part of the individual. [45] Gynan (1985) and [46] Khalil (1985) assert that irritability is the affective response to error, "native speakers' emotional reactions to deviant utterances" (Khalil, 1985: 336). It is the thing that causes people to stop and take notice of a textual feature.In general, irritating errors cause stigmatization. Therefore, [47] Richards (1973) was in consensus that errors which may cause stigmatization should be prioritized. Recently, [35] Ludwig (1982:275) described the irritation continuum as ranging from an "unconcerned, distracted awareness of a communicative trait to a conscious, constant preoccupation with form, to the point that the message is totally obscured or lost".

\section{Subjects}

\section{METHODS}

Fifteen university English teachers contributed in this experimental research. These participants belong to Faculty of Economics and Management of Sfax (FSEGS), Higher Institute of Arts And Crafts, Sfax (ISAMS) and Private Polytechnic Institute of Advanced Science of Sfax (IPSAS), and they are male and female teachers. They are aged between 49 and 60 years. The participants under scrutiny are all native speakers of Tunisian Arabic and the English language is the third one after Arabic and French.

\section{Task Type}

The questionnaire is administered to tertiary level teachers. After collecting and identifying errors the researcher arranged these errors in a scale- item questionnaire (ranking from 1 to 5). The errors are evaluated in their contexts. So the questionnaire is made up of sentences including errors to be evaluated. The errors are classified into five major categories: morphological, lexical, syntactic, mechanical and Miscellaneous errors. The questionnaire was administered twice in relation to error criteria. In other words, at the first time errors are judged according to the acceptability criterion and later errors are re-judged in relation to the irritation criterion. Hence, teachers assigned to each error type two numbers. The first number indicated the seriousness of the error according to the acceptability criterion, whereas, the second number indicates the seriousness of the error according to the irritation criterion. In fact, the more the number increases the more serious the error is. For example, in the acceptability criterion if the first error got 2 and the second error got 5, this means that the second error is more serious than the first one because it is more unacceptable. The errors in the questionnaire are highlighted because the task required from teachers is neither error identification nor error classification; it is rather error seriousness evaluation.

\section{The rationale behind the selected paradigm}

An Error analysis research is carried out following [18] Keshavarz's model (2012:168) which "involves collecting samples of learner language identifying errors, classifying them according to their nature and causes and evaluating their seriousness". The choice of this model is not at random, thus, this model is one of the most recent models in error analysis field of research. Moreover, Keshavarz's mentioning of the evaluation of error seriousness makes his model a good fit to my research requirements. 
The researcher changed the model to fit the research objectives and to craft a tentative model that goes with EG research. As a result, the two first steps in Keshavarz's model remain in situ. Error seriousness explanation, on the other hand, will follow error seriousness evaluation. The latter contains two phases: phase 1 (evaluation on the basis of acceptability criterion), and phase 2 (evaluation on the basis of irritation criterion). Teachers' judgments are situated in the third step of the research model.

This is Keshavarz's (2012) original model:

1- Error identification 2-classification 3-explanation $\quad 4$ - error seriousness evaluation.

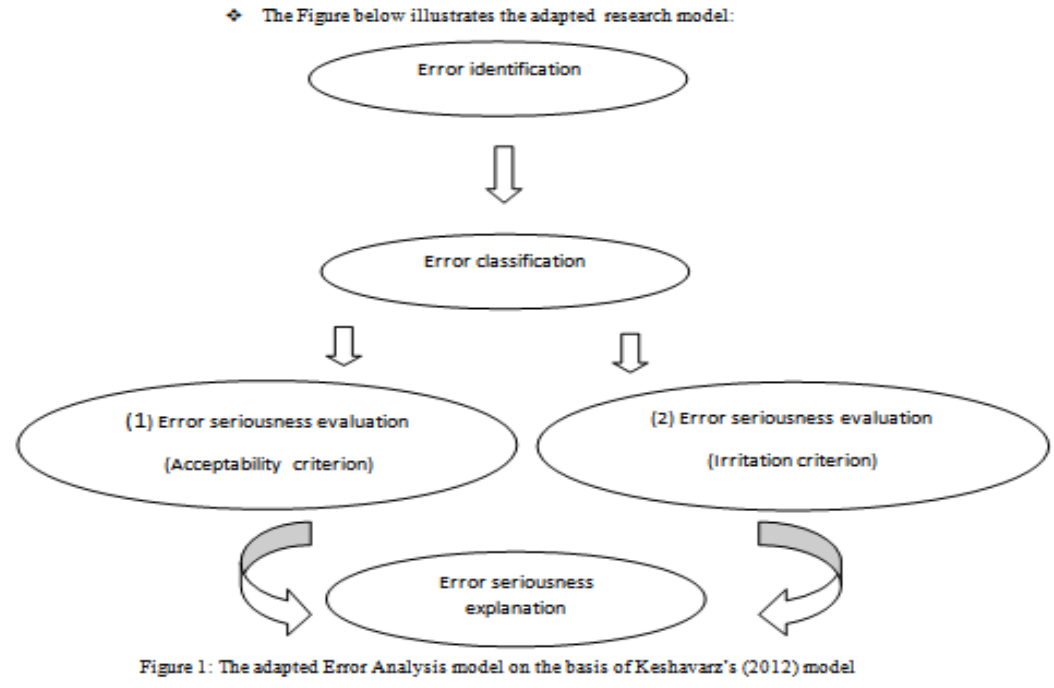

\section{Statistical Tests}

The statistics in this study are based on the (SPSS) statistical tool. It is applied on the data of the questionnaire to extract teachers' variation in responding to the study errors in the light of teaching experience and criteria selection. A two-tailed T-test was used to account for teachers' variability in judging the error seriousness. T-test indicates that there is a significant independence for the equality of means if (p) value is less or equal to (0.05). However, if it exceeds (0.05), we say that T-test indicates no significant independence for the equality of means.

\section{FINDINGS}

\section{Analysis of LTETs judgment of error gravity using acceptability and irritation criteria}

This part compares the severity scores of LTETs response to five error categories using Acceptability and irritation criteria. Figure 2 illustrates the differences in means between these two criteria for LTETs. An independent Samples T-test indicates that there is no significant independence for equality of means between two criteria in judging the gravity of the five error categories $(p=0.083>0.05)$. Therefore Levene's test for equality of variance is valid. Scores were significantly lower for acceptability criterion $(\mathrm{M}=1653, \mathrm{SD}=654)$ than for irritation criterion $(\mathrm{M}=1767,80, \mathrm{SD}=570,54)$. In addition, table (1) presents mean differences of scoring severity of the two criteria in the five categories. Therefore, the analysis will zoom on each error category per se.

\begin{tabular}{|l|l|l|l|l|c|l|l|l|l|l|}
\hline $\begin{array}{l}\text { Teachers' } \\
\text { groups/error } \\
\text { categories }\end{array}$ & \multicolumn{2}{|l|}{ Morphological } & \multicolumn{2}{l|}{ Lexical } & \multicolumn{2}{l|}{ Syntactic } & \multicolumn{2}{l|}{ Mechanical } & \multicolumn{2}{l|}{ misc } \\
\hline & $\bar{X}$ & SD & $\bar{X}$ & SD & $\bar{X}$ & SD & $\bar{X}$ & SD & $\bar{X}$ & SD \\
\hline Acceptability & 406 & 205 & 464 & 206,92 & 416 & 139,75 & 320 & 120,65 & 43,30 & 26,36 \\
\hline Irritation & 426,90 & 152 & 518 & 188,90 & 432 & 127,63 & 342,30 & 115,46 & 62 & 15,96 \\
\hline
\end{tabular}

Table 1. Descriptive Statistics for LTETs' judgment of Acceptability and irritation criteria 


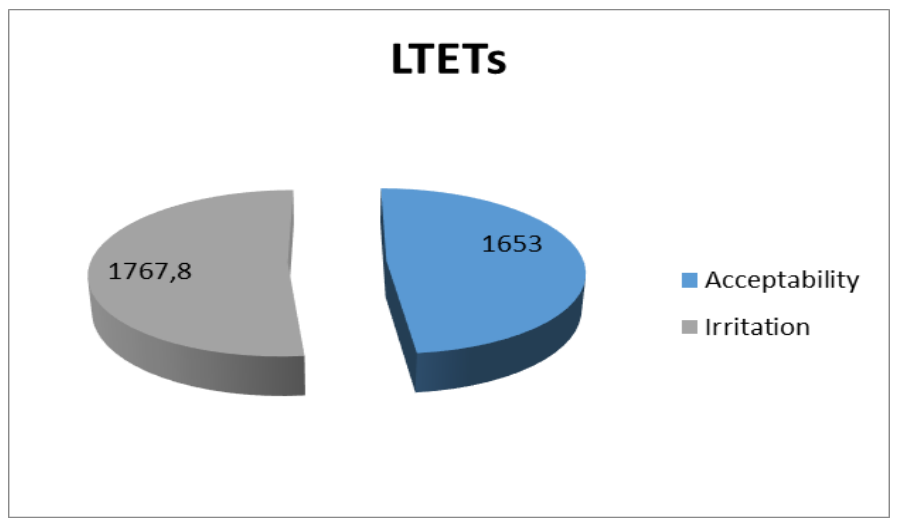

Figure 2: LTETs' differences in error gravity judgment of two criteria

\subsection{Independence between different Morphological error types and the two criteria for LTETs}

An independent Samples T-test indicates that there is no significant independence for equality of means between the two criteria in judging the gravity of Morphological errors $(\mathrm{p}=0.083>0.05)$. For acceptability criterion $(M=406, S D=205)$ and for irritation criterion $(M=426.90, S D=152)$. $T$-test results show that the group of LTETs is more tolerant to Morphological error types irritation judgment than acceptability judgment. We will fine tune the analysis by tackling each Morphological error type per se. Therefore, the means of each error type is used. The figure below presents the severity judgment means of LTETs vis-à-vis the morphological error types using the two criteria. In using acceptability criterion the errors are judged as follows: verb form $(M=159,4)$, noun $(M=61,8)$ adjective $(M=69,7)$, article $(M=59,4)$, subject-verb agreement $(M=55.3)$ verb tense $(M=11.8)$ and adverb $(M=8.4)$, whereas, in using irritation criterion the severity means of these errors are: verb form $(M=167,9)$, adjective $(M=71,3)$, noun $(M=70)$, subject-verb agreement $(M=48,1)$, article $(M=$ 45,3), and adverb $(M=9,2)$ verb tense $(M=6,4)$. These figures show teachers' differences in scoring the morphological error types in adapting two sets of criteria. The analysis of the means of these seven error categories shows the existence of a slight difference between both criteria.

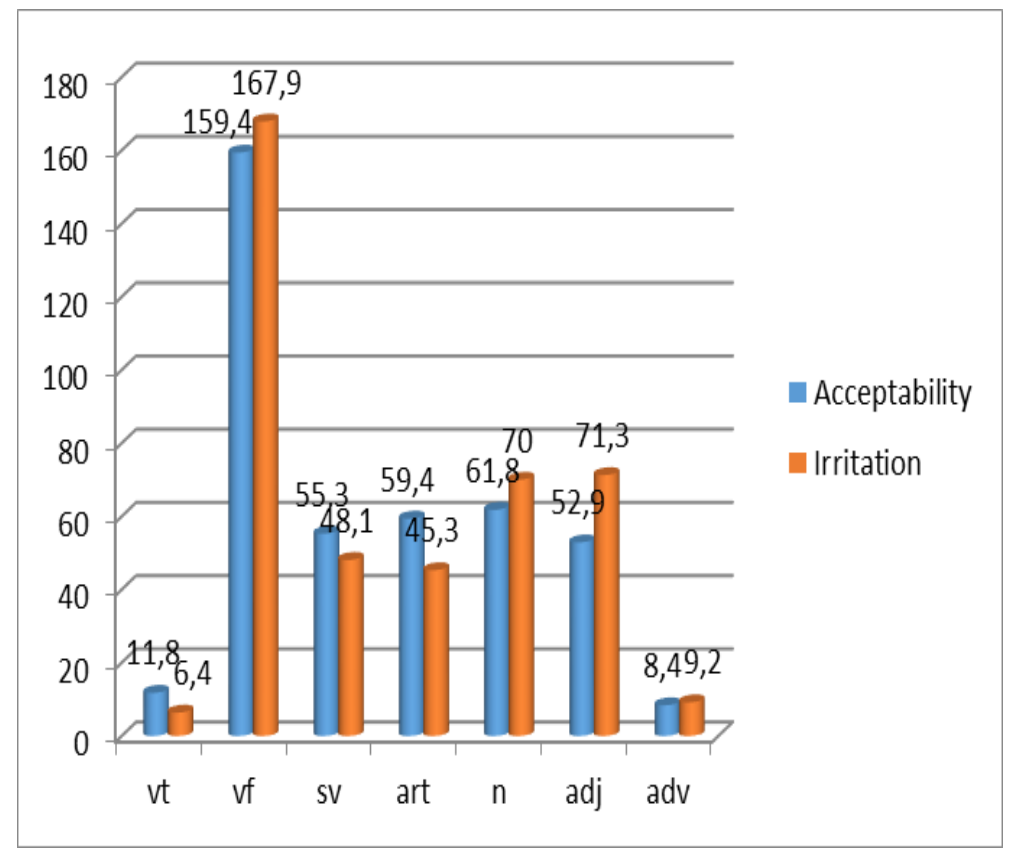

Figure 3: The Morphological Error severity scores distribution of LTETs for the two criteria

\subsection{Independence between different Lexical error types and the two criteria for LTETs}

An independent Samples T-test indicates that there is no significant independence for equality of means among LTETs in adapting two different sets of criteria in judging the gravity of Lexical errors $(\mathrm{p}=$ $0.083>0.05)$. For acceptability criterion $(M=464, S D=206.92)$ and for irritation criterion $(M=518, S D=188.90)$. 
The figure below illustrates the severity judgment of LTETs vis-à-vis the Lexical error category which is composed of four error types. They judge the severity of these errors according to acceptability as follows: word choice $(M=346.4)$, word form $(M=83.3)$, pronoun $(M=34.6)$ and collocation $(M=26.6)$ whereas, lexical error

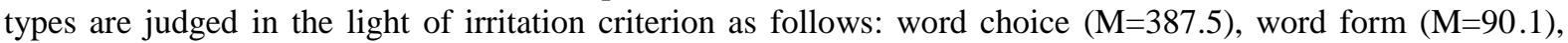
pronoun $(\mathrm{M}=40.6)$ and collocation $(\mathrm{M}=30.2)$. The means are higher for irritation criterion than for the acceptability one.

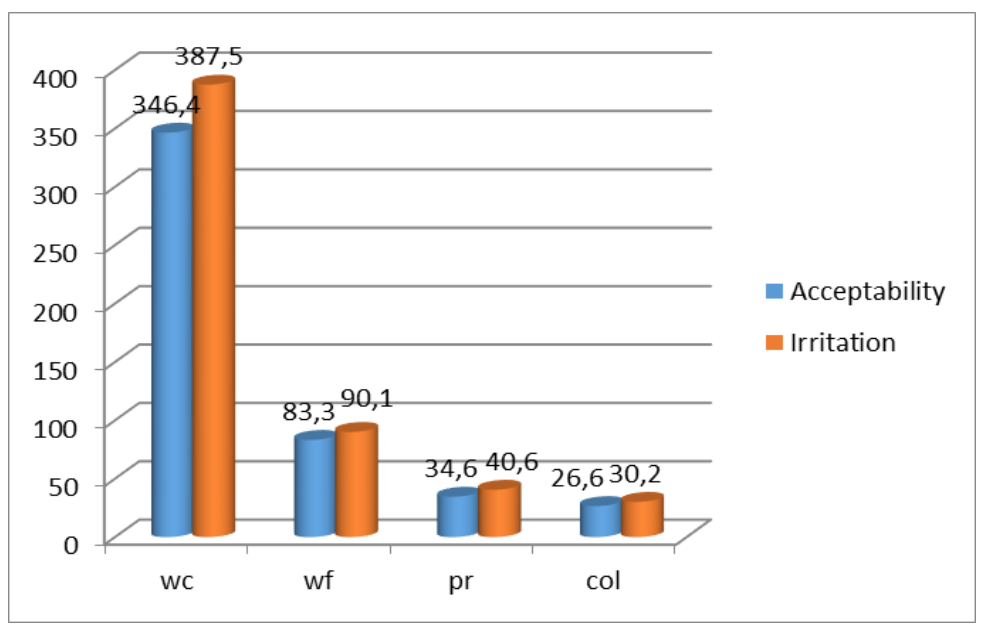

Figure 4: The Lexical Error severity scores distribution of LTETs for the two criteria

\subsection{Independence between different Syntactic error types and the two criteria for LTETs}

An independent Samples T-test indicates that there is a significant independence for equality of means between two criteria in judging the gravity of Syntactic errors $(p=0.00<0.05)$. For acceptability criterion $(M=$ $416 \mathrm{SD}=139.75)$ and for irritation criterion $(\mathrm{M}=432, \mathrm{SD}=127.63)$. A comparison of means shows that LTETs judge the severity of errors in using acceptability as follows: $(M=228.1)$ sentence structure, $(M=118.7)$, fragmentation $(M=19.2)$ run-ons whereas, in adapting the irritation criterion $(M=252.5)$ sentence structure, $(\mathrm{M}=48.9)$ fragmentation and $(\mathrm{M}=101)$ run-ons. The figures show that there is a discrepancy of means in runons and fragmentation from one criterion to another.

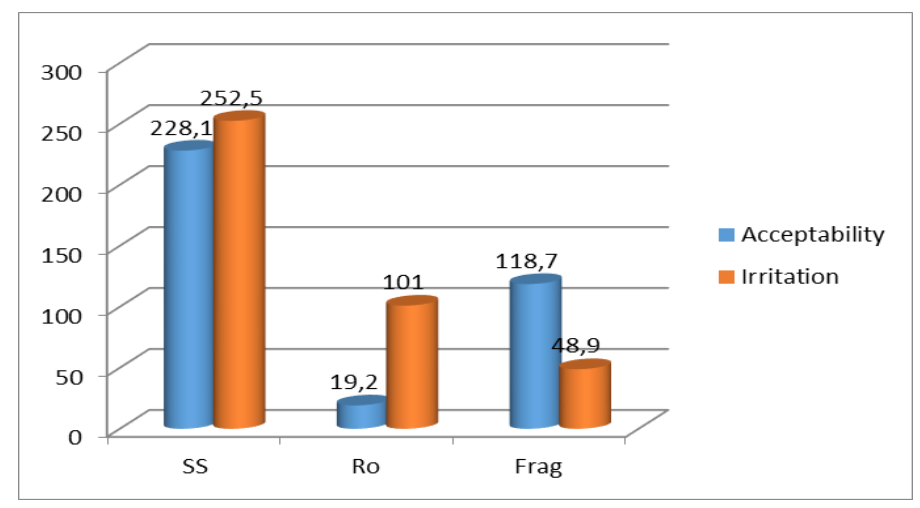

Figure 5: The Syntactic Error severity scores distribution of LTETs for the two criteria

\subsection{Independence between different Mechanical error types and the two criteria for LTETs}

An independent Samples T-test indicates that there is a significant independence for equality of means between two criteria in judging the gravity of Mechanical errors $(p=0.00<0.05)$. Scores were significantly higher for irritation $(M=342.30, S D=115.46)$ and for acceptability $(M=320, S D=120.65)$. The figure below illustrates the severity judgment of LTETs vis-à-vis the Mechanical error category in implementing two sets of criteria. They judge the severity of these errors as follows: For acceptability criterion $(\mathrm{M}=34.6)$ punctuation and $(\mathrm{M}=304.8)$ spelling. However, for irritation, criterion errors are prioritized as follows: $(\mathrm{M}=268,9)$ punctuation and $(\mathrm{M}=73.4)$ spelling. $\mathrm{T}$-test indicates a significant independence for equality of means in these two error types between the two criteria $(\mathrm{p}=0.00<0.05)$. 


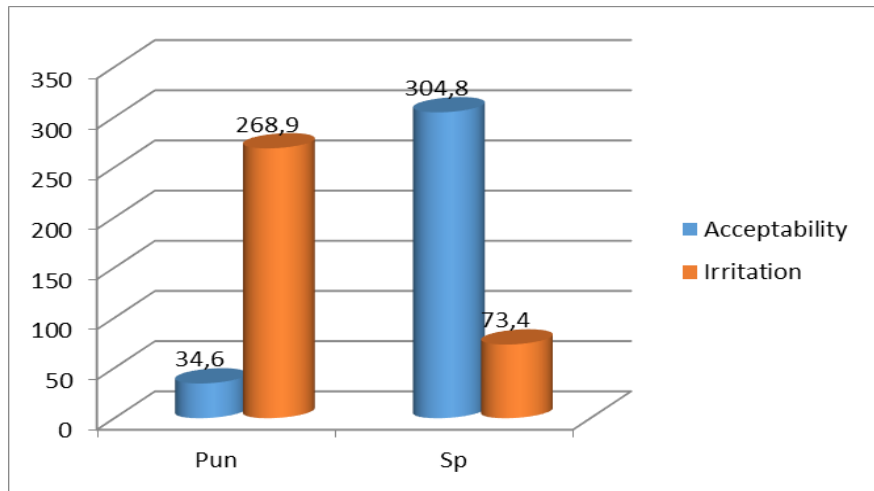

Figure 6: The Mechanical Error severity scores distribution of STETs for the two criteria

\subsection{Independence between different error Miscellaneous types and the two criteria for LTETs}

An independent Samples T-test indicates that there is no significant independence for equality of means between two groups of teachers in judging the gravity of Miscellaneous errors $(\mathrm{p}=0.083<0.05)$. Scores were higher for irritation criterion $(\mathrm{M}=62, \mathrm{SD}=15.96)$ than for acceptability $(\mathrm{M}=43.30 \mathrm{SD}=26.36)$. As a result, the scores record no gravity evaluation variability between two criteria.

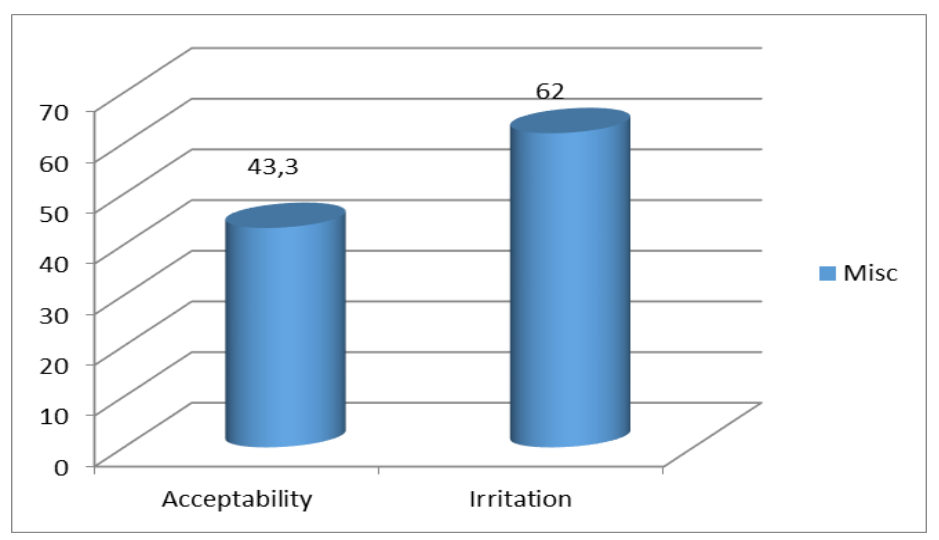

Figure 7: The Miscellaneous Error severity scores distribution of LTETs for the two criteria

2. Analysis of the hierarchical order of errors according to acceptability and irritation criteria of LTETs

Table 2. Comparative error gravity Hierarchies of LTETs group in both criteria

\begin{tabular}{|l|l|l|l|l|l|}
\hline & 1 & 2 & 3 & 4 & 5 \\
\hline 1)Acceptability & $\begin{array}{l}\text { Lexical } \\
\text { errors } \\
\text { word } \\
\text { choice } \\
\text { word form } \\
\text { pronoun } \\
\text { collocation }\end{array}$ & $\begin{array}{l}\text { Syntactic } \\
\text { errors } \\
\text { fragmentation } \\
\text { run-ons } \\
\text { sentence } \\
\text { structure }\end{array}$ & $\begin{array}{l}\text { Morphological } \\
\text { errors } \\
\text { verb form } \\
\text { noun } \\
\text { article } \\
\text { subject verb } \\
\text { agreement } \\
\text { adjective } \\
\text { adverb } \\
\text { verb tense }\end{array}$ & $\begin{array}{l}\text { Mechanical } \\
\text { errors } \\
\text { punctuation } \\
\text { spelling }\end{array}$ & $\begin{array}{l}\text { Miscellaneous } \\
\text { errors }\end{array}$ \\
\hline 2) Irritation & $\begin{array}{l}\text { Lexical } \\
\text { errors } \\
\text { word } \\
\text { choice } \\
\text { word form } \\
\text { pronoun } \\
\text { collocation }\end{array}$ & $\begin{array}{l}\text { Syntactic } \\
\text { errors } \\
\text { sentence } \\
\text { structure } \\
\text { run-ons } \\
\text { fragmentation }\end{array}$ & $\begin{array}{l}\text { Morphological } \\
\text { errors } \\
\text { verb form } \\
\text { adjective } \\
\text { noun } \\
\text { subject verb } \\
\text { agreement }\end{array}$ & $\begin{array}{l}\text { Mechanical } \\
\text { errors } \\
\text { punctuation } \\
\text { spelling }\end{array}$ & $\begin{array}{l}\text { Miscellaneous } \\
\text { errors }\end{array}$ \\
\hline
\end{tabular}




\begin{tabular}{|l|l|l|l|l|l|}
\hline & & $\begin{array}{l}\text { article } \\
\text { adverb } \\
\text { verb tense }\end{array}$ & & \\
& & & & \\
\hline
\end{tabular}

The ranking of errors is the same from one criterion to another for LTETs. Therefore, they are very consistent in their error gravity evaluation of the five error categories. To conclude, LTETs find lexical errors the most unacceptable error category followed by Syntactic, Morphological, Mechanical and Miscellaneous errors. Similarly, they find Lexical errors the most irritating error category followed by Syntactic, Morphological, Mechanical and Miscellaneous errors. In an attempt to fine-tune our analysis, we can zero on the different error types under each category. As a matter of fact, LTETs have the same priorities of lexical, mechanical and miscellaneous error types except for syntactic and morphological ones. As far as syntactic errors are concerned, the hierarchy in acceptability criterion is as follows: fragmentation, run-ons, and sentence structure. Whereas in irritation criterion becomes as follows: sentence structure, run-ons, and fragmentation. In addition, the hierarchies present a difference in prioritizing morphological error types. In acceptability criterion, we have the following order: verb form, noun, article, subject-verb agreement, adjective, adverb, and verb tense. And within irritation criterion errors ranking becomes verb form, adjective, noun, subject-verb agreement, article, adverb, verb tense. As a result, we can draw some conclusions about the correlation between Acceptability and Irritation criteria vis-à-vis error categories. In this research, lexical errors are the most serious. Therefore, the explanation will focus only on this category. In fact, $30 \%$ of lexical errors are intralingual and $70 \%$ of lexical errors are interlingual. So, Arabic and French languages are the main source of lexical errors.

\section{DISCUSSION}

The study findings show that teachers' judgment vary in adapting different judgment criteria. This statement may be explained by the nature of error judgment itself which is a very subjective task "..... which is likely to lead to considerable variations in judgment between one teacher and another" [48] (Davies 1983:6869). Moreover, having different sets of criteria engenders more differences in the evaluation of the same error. In our study we have used two different criteria and the results show that teachers differ in the error seriousness evaluation of the five error categories in considering irritation and acceptability measures. [49] James (1977) seems to support the view when he says that ESL teachers probably" do refer consistently to criteria of degrees of erroneousness when they mark, even though they do not explicitly formulate these criteria". (p: 116) Acceptability as a criterion in error evaluation helps to determine the gravity of an error, that is, the extent to which we can accept or reject an error. This is why [50] Valettee (1977) calls the process, 'Level of error tolerance', and this considerably influences our attitude towards the answer scripts of students. In fact, deciding upon the acceptability of errors is not an easy task and requires a great cognitive readiness on the part of a teacher. This severity consideration may be explained by [33] Bachman (1990) model of communicative competence with may explain teachers' judgment of acceptability. Hence, teachers' reactions could be explained by two main types of competencies. First, organizational competence is concerned with grammatical and textual competencies, i.e, the acceptance of accuracy and fluency of the written piece of discourse. Second, illocutionary and sociolinguistic competencies, i.e, the pragmatic effect of the discourse. In fact, deciding upon the acceptance of an utterance is related to one of these competencies. This model frames our understanding of acceptability. The analysis results show that the group of LTETs is more severe when adapting irritation criterion rather than the acceptability one. The tolerance in adapting acceptability criterion can be explained by LTETs better knowledge of the wide variety of acceptable structures of the language. LTETs are familiar with students' deviant structures, i.e, their range of acceptable structures are very wide. This result goes with [51] Lyster's (2004: 410) statement that experienced teachers often learn to interpret their students' interlanguage. Thus they might have difficulties in distinguishing errors which impede understanding and those which do not. Although, our research focuses on non-native English speakers, the current research findings replicate those related to native speakers. For example, similar findings were found in [52] Hughes and Lascaratou (1982) conclusions that Native Speakers were found to mark more leniently than Non Native teachers. In addition, Native Speaker judges tend to judge lexical errors as more serious than grammatical errors ([53] Burt 1975, [54] Tomiyana 1980).The latter conclusion will be covered in the next part related to error hierarchies where both groups of teachers prioritize lexical errors on the expense of other error categories. As a matter of fact, LTETs and native speakers behave similarly in approaching learners' errors in the light of irritation criterion. This conclusion leads us to think about the concept of 'native speakerism'. Therefore, when it comes to teaching practice, we can draw a line between a native English speaker and a native English practitioner. For the native English speaker, we address the teacher's competence. However, for a native English practitioner, we address the teacher's actual performance. This dichotomy is valid only when we compare the practice of native and nonnative English speakers. This conclusion cements Selinkers' claim that only 5\% of non-native speakers may 
reach the degree of native speakers. However, LTETs are more severe in judging the errors in the light of irritation criterion because they stigmatize and bother the reader. Irritation is defined as the result of the form of the message intruding upon the interlocutor's perception. This criterion is of a paramount importance. Apart from this study, it has been used in studies by [55] Piazza (1979), [56] Chastain (1980 a), [57] Galloway (1980), and [58] Magnan (1981). The rationale behind choosing criteria selection as a main variable in this piece of research is to come up with different error hierarchies. These hierarchies highlight the importance of perspectives. Therefore, [59] Davies (1983:310) asserts that".... Any error evaluation will be colored by the particular viewpoint from which it is carried out, and thus may not be consistent with evaluations made from other viewpoints". Davies' claim seems to be valid in this part of discussion because both groups of teachers differ in gravity judgment in the light of criterion choice. Therefore, we can get different error gravity hierarchies based on these two variables. The need to establish error hierarchies in this research is rooted in many error gravity studies. Therefore, error gravity hierarchies have been investigated for Second and foreign language classes in English ([60] MC Cretton and Rider 1993, and [61] Davies 1983). These studies tend to establish hierarchies of errors that can be used as an aid for teachers to assess the students' written work. It appears to be a universal concern to prioritize errors. It could be explained by the human cognitive potential that tends to create hierarchies of difficulties which make the processing of knowledge easier. Therefore, human error processing appears to be hierarchically organized regarding the different complex neural systems ([62] Doya, 2000; [63] Doya et al, 2001). When considering acceptability criterion, the teaching experience appears to have an impact on teachers ranking of errors. Therefore, LTETs consider lexical errors as the most unacceptable error category followed by syntactic, morphological, mechanical and miscellaneous errors. The two extremes remain situ whereas; the three other categories have witnessed a total reshuffle which mirrors teachers' evaluation preferences. These findings seem to stand in stark contrast to a host of research findings which hold the mainstream assumption that consider "....all errors to be equally serious" ([64] Van Meyer and Lorenz, 1984) LTETs perceive lexical errors as the most irritating which are followed by syntactic, morphological, mechanical and miscellaneous errors. In adapting irritation criterion both groups prioritize errors differently. We come up with two irritation continua in which error categories could be classified as [35] Ludwig (1982:275) described from an "unconcerned, distracted awareness of a communicative trait to a conscious, constant preoccupation with form, to the point that the message is totally obscured or lost". As a matter of fact, we have different classifications. Therefore, the difference in the hierarchical order of the five error categories is explained by the effect of teaching experience in the seriousness judgment of teachers. This cements the impact of experience in shaping severity differences between teachers. LTETs do not differ in judging the gravity of errors while adapting acceptability and irritation criteria. The errors are prioritized as follows in both criteria: lexical errors, syntactic errors, morphological errors, mechanical errors and miscellaneous errors. This consistency in adapting both criteria without any change in the priority of errors reflects the role of experience in achieving consistent evaluation among teachers. [65] Myford and Wolfe (2009) called for research on the impact of rater experience on the stability of rater severity. Their findings indicated that there was more instability when raters are less experienced. Experienced teachers can automate well-learned routines, they achieve this because their cognitive skills become automatic with extensive practice [66] (Chi et al, 1981). They achieve this because their cognitive skills become automatic with extensive practice [67] (Chase \& Simon, 1973).The analysis of the study findings shows that there is a consensus upon the priority of lexical error category in acceptability and irritation criterion and by both groups of teachers. The findings corroborate with those of [68] Hamdi, S (2016) which suggest that Tunisian EFL learners face more difficulties with lexical formal errors. Also, the findings echo those of Sheory's research in which lexical errors are perceived as the most serious error category in his error gravity hierarchy (p: 310). In addition, [69] Ellis (1994: 63) confirms that "Researchers who have delt with the evaluation of errors have found out that lexical errors are considered the most serious, above all". Therefore, the most serious error category should be explained to understand the sources of lexical errors [70] Abott (1980:124) puts it:"The aim of an EA is to provide a psychological explanation". Recent studies ([71] Bitchener,Youth and Cameron, 2005, and [72] Sheen 2007) have shown that when written corrective feedback is focused it is effective in promoting acquisition. [73] Svartvik (1973:13) asserts that Error Analysis may help the teacher to set up a hierarchy of difficulties and to achieve a realistic ranking of teaching priorities at different levels. In fact prioritizing errors has a pragmatic dimension because error analysis helps teachers build their teaching priorities in an informed way. For example, according to [74] Richards and Sampson (1974: 15), "At the level of pragmatic classroom experience, error analysis will continue to provide one means by which the teacher assesses learning and teaching and determines priorities for future effort." Making a focused written corrective feedback promotes acquisition [75] (Ellis et al 2008). 


\section{IMPLICATIONS FOR TEACHING}

The findings in the present study might offer some implications for the Tunisian teachers since the major objective of this research is to provide insights about teachers' error treatment judgment of the seriousness of students' written errors through testing the impact of teaching experience and criteria selection. The first implication that emerges from the findings is to teach with a hierarchy in mind. That is to say, teachers' prioritization of errors facilitates their job and enables them to prioritize their teaching objectives because they become aware of their students' hierarchies of difficulties. Also, accounting for teachers' areas of severity and tolerance helps learners notice the gap in their learning and know more about their serious errors that bother them in their learning process. The second implication centers on the importance of criteria in error judgment. Therefore, Tunisian teachers should be aware that errors are not serious by themselves, but the way we approach them through the choice of our criteria makes the difference in accounting for their gravity. Therefore, teachers' awareness should be drawn to the impact of criteria selection on their teaching practice and self-reflection because "reflecting on [corrective feedback] serves as a basis both for evaluating and perhaps changing existing [corrective feedback] practices and, more broadly, for developing teachers' understanding of teaching and of themselves" [76] (Ellis, 2009: 15). The third implication emanates from our concern with the teaching experience. So, it is preferable to blur these boundaries through exchanging experiences and enriching their experiences dialogically. The forth implication holds the label 'errors we live by". Therefore teachers can build their teaching pedagogies on the most serious errors and hardships extracted from their learners either in a classroom context or in a no-contact context. Finally, this research has an impact on curriculum design for Tunisian university teachers. For example, instead of having each syllabus to each faculty, we can make a national curriculum based on the most serious errors committed by our students on the basis of different criteria. Therefore, the objectives of the curriculum become tailored around the learners' errors. As [77] Lee (2011:9) notes, "teacher education holds the key to helping teachers understand the need to change and improve their feedback practices, as well as equipping them with the knowledge and skills to implement change".

\section{RECOMMENDATIONS FOR FUTURE RESEARCH}

One important area that should be investigated in future research is the effectiveness of teachers' error gravity evaluation in writing. In order to major the effect of this evaluation on the progress of students' performance in writing, the teacher draws learners' attention to the most serious error according to a welldefined criterion and then provides them with tasks including these most serious errors. Each time, the researcher should measure students' progress through decreasing students' errors. In addition, another area that deserves investigation consists in measuring whether error gravity evaluation contributes to teachers' professional development or not. This will be clear through examining the effect of teachers' evaluation of the seriousness of certain errors on their pedagogical orientations in theory and practice. Importantly, as [77] Lee (2011) argues, "there is a need to look beyond the issue of feedback per se to investigate teachers' readiness to implement change as well as the factors that might facilitate or inhibit change" (p. 10). Moreover, another area of research should be the explanation of teachers' error seriousness variation. Therefore, we can major the different causes that make some teachers more severe than others in judging the gravity of certain errors.

\section{CONCLUSION}

This piece of research attempts to provide a value to teachers' error gravity evaluation of written errors. The findings revealed that teachers' seriousness depends on the criteria selection. In fact, this research could contribute to "developing empirical models of second-language writing instruction that do justice to the full nature of this phenomenon" [78] (Cumming, 2001, p. 209). Moreover, it provided an opportunity "to share insights, experiences, and tools across universities, particularly as many are solely responsible for teachers' professional development in their department" [79] (Allen \& Negueruela-Azarola, 2010, p. 389). In addition, focusing on students' written errors raises the awareness of teachers to be more humanistic in their treatment. Establishing a bridge between the ESL teacher and the SLA researcher remains the ultimate goal of this research in order to make theory into practice and to rely on practitioners' practice to shape a good theory of teaching because "there is nothing more practical than a good theory [80] (Lewin, 1952: 169).

\section{REFERENCES}

[1] Eun-pyo, L. (2002). Error analysis on medical students ${ }^{e e}$ writing. Eulji University, School of Medicine. http://www.paaljapan.org/resources/proceedings/PAAL8/pdf/pdf053.pdf.

[2] Kasanga, L. A. (2006). Requests in a South African variety of English, pp 1; 65-89. www.nie.edu.sg/profile/kasangaluangaadrien- 0 .

[3] Rivers, W and Temperley, M (1978). A practical Guide to the Teaching of English as a Foreign or Second Language. New York: Oxford University Press. ISBN0-19-502210-6 
[4] AbiSamra, N. (2003).An analysis of errors in Arabic speakers' English writing. In Mourtaga, K. (Ed.), Investigating writing problems among Palestinian students studying English as a foreign. Unpublished language doctoral dissertation.

[5] Raimes, A. (1991). Errors: Windows into the Mind. College ESL, 1(2), 55-64.

[6] Ellis, R. (2003). Task-based language learning and teaching. Oxford: Oxford University Press

[7] Yule, G. (2010). The study of language. (4th ed.).Cambridge: Cambridge

[8] James, C. (1998). Errors in language learning and use. New York: Longman.

[9] Corder, S. (1967). The significance of learners'errors. International Review of Applied Linguistics, 5(4), 161-169.

[10] [Richard, J.C. \& Schmidt, R. (Eds.). (2002). Longman dictionary of language teaching and applied linguistics (3rd ed.). London: Longman.

[11] Crystal, D. (2003). A dictionary of linguistics and phonetics (5th ed.). London: Blackwell. http://doi.wiley.com/10.1002/9781444302776

[12] Corder, S. (1974). Error Analysis, In Allen, J.L.P. and Corder, S.P. (1974). Techniques in Applied Linguistics. Oxford: Oxford University Press.

[13] Xie F and Jiang X (2007). Error analysis and the EFL classroom teaching. US-China Education Review, 4(9), pp.1014.

[14] Corder, S. (1967). The significance of learners'errors. International Review of Applied Linguistics, 5(4), 161-169.

[15] Corder, S. (1973). Introducing Applied Linguistics. Harmondsworth, U.K.: Penguin Books.

[16] Ellis, R. (1994). The studies in second language acquisition. Oxford: Oxford University Press.

[17] Gass, S.M., \& Selinker, L. (2008). Second Language Acqusition: An Introductory Course: Taylor \& Francis Group

[18] Keshavarz, M. (2012). Contrastive analysis and error analysis (2nd ed.). Tehran: Rahamana Press.

[19] Paltridge, B. (2004). Academic writing. Language Teaching, 37, 87-107.

[20] Burt, M. K. (1975). Error analysis in the adult EFL classroom. TESOL Quarterly, 9(1), 53-63.

[21] Valdman, Albert . 1975. 'Learner Systems and Error Analysis' . In Jarvis, Gilbert A. (ed), Perspective : A New Freedom. Skokie IL: National Textbook Co.

[22] Ellis, N. C. (2013). Second language acquisition. In Oxford Handbook of Construction Grammar (pp. 365-378), G. Trousdale \& T. Hoffmann (Eds.). Oxford: Oxford University Press. SecondLanguageAcquistionCxGPreprint.pdf

[23] Delisle, H. (1982). Native speaker judgment and the evaluation of errors in German. The Modern Language Journal, 66(1), 39-48.

[24] Ellis, R. (2008). The study of second language acquisition (2nd ed.). New York: Oxford University Press.

[25] Lee, I. (2003). L2 writing teachers' perspectives, practices and problems regarding error feedback. Assessment Writing, 8, 216-237.

[26] Hammerly, H. (1991). Fluency and accuracy: Toward balance in language teaching and learning. Clevedon: Multilingual Matters LTD.

[27] Burt, M. K. (1975). Error analysis in the adult EFL classroom. TESOL Quarterly, 9(1), 53-63.

[28] Ferris, D. R. (2002). Treatment of error in second language student writing. Ann Arbor, MI:The University of Michigan Press.

[29] James, C. (1977). Judgments of error gravities. English Language Teaching Journal, 2, 116124

[30] Hyland, F. and Hyland, K. (2006) Feedback on Second Language Students' Writing. Lang. Tech., 39: 83-101. Cambridge: Cambridge University Press.

[31] Ferris, D. R. (1999). The case for grammar correction in L2 writing classes: A response to Truscott (1996). Journal of Second Language Writing, 8(1), 1-11

[32] Bartram, M., \& Walton, R. (1991). Correction. Hove, England: Language Teaching Publications.

[33] Bachman, L. F. (1990). Fundamental Consideration in Language Testing. Oxford: OUP.

[34] Corder, S. (1973). Introducing Applied Linguistics. Harmondsworth, U.K.: Penguin Books.

[35] Ludwig, J. (1982). Native-speaker judgments of second-language learners'efforts at Communi cation: A review. The Modern Language Journal, 66(3), 274-283.

[36] Vann, R. J., Meyer, D. E., \& Lorenz, F. O. (1984). Error gravity: A study of faculty opinion of ESL errors. TESOL Quarterly, 18(3), 427-440.

[37] Santos, T. (1988). Professors' reactions to the academic writing of nonnative-speaking students. TESOL Quarterly, 22(1), 69-90.

[38] Khalil, A. (1985). Communicative error evaluation: Native speakers' evaluation and interpretation of written errors of Arab EFL learners. TESOL Quarterly, 19(2), 335-351.

[39] Piazza, L. G. (1979). Communicative Effects of Grammatical Errors Made by American Learners of French. Ph.D. Dissertation, University of Rochester.

[40] Chastain, K. (1980). Native speaker reaction to instructor-identified student second-language errors. The Modern Language Journal, 64(2), 210-215.

[41] Galloway, V. B. (1980). Perceptions of the communicative efforts of American students of Spanish. The Modern Language Journal, 64(4), 428-433.

[42] Ensz, K. Y. (1982). French attitudes toward typical speech errors of American speakers of French. The Modern Language Journal, 66(2), 133-139.

[43] Santos, T.(1987). Markedness theory and error evaluation : an experimental study. Applied Linguistics, 8,207-218.

[44] Vann, R. J., Meyer, D. E., \& Lorenz, F. O. (1984). Error gravity: A study of faculty opinion of ESL errors. TESOL Quarterly, 18(3), 427-440.

[45] Gynan, S. N. (1985). Comprehension, irritation, and error hierarchies. Hispania, 68(1), 160-165. 
[46] Khalil, A. (1985). Communicative error evaluation: Native speakers` evaluation and interpretation of written errors of Arab EFL learners. TESOL Quarterly, 19(2), 335-351.

[47] Richards, J.C. (ed). (1973). Error Analysis. London: Longman.

[48] Davies, E.E., (1983). Error evaluation: the importance of viewpoint. English Language Teaching Journal 37 (4),304311.

[49] James, C. (1977). Judgments of error gravities. English Language Teaching Journal, 2, 116124

[50] Valette, R.1977: Modern language testing. Second edition. San Diego, CA: Harcourt Brace Jovanovich.

[51] Lyster, R. (2004). Differential effects of prompts and recasts in form-focused instruction. Studies in Second Language Acquisition, 26(3), 399-432.

[52] Hughes, A., \& Lascaratou, C. (1982). Competing criteria for error gravity. ELT Journal, 36(3),175-182.

[53] Burt, M. K. (1975). Error analysis in the adult EFL classroom. TESOL Quarterly, 9(1), 53-63.

[54] Tomiyana, M. (1980). Grammatical errors communication breakdown. TESOL Quarterly, 14(1) 71-79.

[55] Piazza, L. G. (1979). Communicative Effects of Grammatical Errors Made by American Learners of French. Ph.D. Dissertation, University of Rochester.

[56] Chastain, K. 1980(a). "Native Speaker Reaction to Instructor-Identified Student Second Language Errors," Modern Language Journal 64(2):210-215.

[57] Galloway, V. B. (1980). Perceptions of the communicative efforts of American students of Spanish. The Modern Language Journal, 64(4), 428-433.

[58] Magnan, S. S (1983). Age and sensitivity to gender in French. Studies in Second Language Acquisition, 5, 194-212.

[59] Davies, E.E., (1983). Error evaluation: the importance of viewpoint. English Language Teaching Journal 37 (4), $304-$ 311.

[60] McCretton, E., \& Rider, N. (1993). Error gravity and error hierarchies. International Review of Applied Linguistics in Language Testing, 31(3), 177-188.

[61] Davies, E.E., (1983). Error evaluation: the importance of viewpoint. English Language Teaching Journal 37 (4) ,304311.

[62] Doya, K. (2000). Complementary roles of basal ganglia and cerebellum in learning and motor control. Current Opinion in Neurobiology, 10(6), 732-739.

[63] Doya, K., Kimura, H., \& Kawato, M. (2001). Computational approaches to neural mechanisms of learning and control. IEEE Control Systems Magazine, 21(4), 42-54.

[64] Vann, R. J., Meyer, D. E., \& Lorenz, F. O. (1984). Error gravity: A study of faculty opinion of ESL errors. TESOL Quarterly, 18(3), 427-440.

[65] Myford, C. M., and Wolfe, E. M. (2009). Monitoring rater performance over time: A framework for detecting differential accuracy and differential scale use. Journal of Educational Measurement, 46, 371-389.

[66] Chi, M. T., Feltovich, P. J., \& Glaser, R. (1981). Categorization and representation of physics problems by experts and novices. Cognitive Science, 5, 121-152.

[67] Chase, W.G., and H.A. Simon (1973). Perception in chess. Cognitive Psychology 1:33-81.

[68] Hamdi, S. (2016). An analysis of lexical errors in the English compositions of EFL Tunisian learners. International Journal of Humanities and Cultural Studies, vol 2, (4).

[69] Ellis, R. (1994). The studies in second language acquisition. Oxford: Oxford University Press.

[70] ABBOT, G. 1980. "Towards a more rigorous error analysis.” International Review of Applied Linguistics 18.2: 121133.

[71] Bitchener, J., Young, S., \& Cameron, D. (2005). The effect of different types of corrective feedback on ESL student writing. Journal of Second Language Writing, 14, 91-205.

[72] Sheen, Y. (2007). The effect of focused written corrective feedback and language aptitude on ELS learners' acquisition of articles. TESOL Quarterly, 41(2), 255-284.

[73] Svartvik. J. (1973). Errata; Papers in error artalysis. Lund, Sweden; Gleemp.

[74] Richards, J. C., \& Sampson, G. P. (1974). The Study of Learner English. In J. C. Richards (Ed.), Error Analysis: Perspectives on Second Language Acquisition (pp. 3_18). London: Longman

[75] Ellis, R., Sheen, Y., Murakami, M., \& Takashima, H. (2008). The effects of focused and unfocused written corrective feedback in an English as a foreign language context. System, 36, 353-371.

[76] Ellis, R. (2009). A typology of written corrective feedback types. ELT 63 (2), 97-107.

[77] Lee, Icy (2011). Feedback revolution: what gets in the way? ELT Journal 65: 1-12.

[78] Cumming, A. (2001). Learning to write in a second language: Two decades of research. International Journal of English Studies, 1(2), 1-23.

[79] Allen, H. W., \& Negueruela-Azarola, E. (2010). The professional development of future professors of foreign languages: Looking back, looking forward. Modern Language Journal, 94, 377-395.

[80] Lewin, K (1952). "Group decision and social change." In G. E. Swanson, T. M. Newcomb, and E. L. Hartley (eds.), Readings in So- cial Psychology: 459-473. New York: Holt 